\title{
De mãos limpas com as tecnologias digitais
}

\author{
Monica Erika Pardin Steinert \\ Professora de Biologia - SEDUC/MT \\ Mestranda em Ensino de Ciências Naturais - PPGECN/UFMT \\ $\triangle$ pardiste76@hotmail.com \\ Edna Lopes Hardoim \\ Doutora em Ecologia - UFsCAR \\ Docente na UFMT- Instituto de Biologia \\ Maria P.P.R.Castro Pinto \\ Professora de Química - SEDUC/MT \\ Mestra em Saúde e Ambiente - UFMT
}

Recebido em 11 de agosto de 2016

Aceito em 24 de outubro de 2016

\begin{abstract}
Resumo:
As tecnologias digitais são difundidas entre os jovens, personificadas principalmente por telefones celulares e modernos smartphones, como ferramentas praticamente onipresentes no seu cotidiano. A despeito da reiterada cultura de resistência (já muito discutida, mas não superada) a esses dispositivos por parte de muitos docentes, seu uso recreativo também persiste. Diante de tal demanda, este artigo, que consiste em um relato de experiência, tem o objetivo de demonstrar a execução de uma proposta de ensino-aprendizagem baseada em Biologia e Química, que buscou perceber possibilidades e limitações ao uso de tecnologias digitais móveis - m-learning - e computadores via metodologia híbrida sustentada de ensino. Essa proposta, que ocorreu em escola pública de ensino médio em Cuiabá, MT, teve como foco temático a prevenção a doenças infectocontagiosas potencialmente transmissíveis pelo manuseio de dispositivos digitais. Um protótipo de aplicativo de celular e um blog foram utilizados no processo, para surtir como ferramentas midiáticas digitais, buscando um potencial enquadramento na teoria de aprendizagem de George Siemens, o Conectivismo. As informações nesses objetos constariam como nós em uma rede de informações, receptiva ao feedback dos discentes, enquanto participantes ativos dessa mesma rede. Na experiência, obstáculos diversos ficaram evidentes para a implementação de práticas de semelhante natureza e propósito na escola pública, particularmente, de âmbito formativo, logístico e recursivo. Algo que admoesta aos interessados nessas ações, cautela em seu planejamento e execução. Entretanto, alternativas plausíveis também podem ser consideradas, evidenciando que o ensinoaprendizagem baseado em metodologias digitais e redes, não é impossível para este setor tão combatido e sofrido da educação básica, uma vez que é preconizado por organismos internacionais como a UNESCO. Palavras-chave: Saúde; Higiene; Ensino híbrido; Conectivismo; Celulares.
\end{abstract}

\section{Of clean hands with digital technologies}

\begin{abstract}
:
Digital technologies are widespread among young people, personified mainly by mobile phones and modern smartphones, as tools almost ubiquitous in their daily lives. In spite of the repeated culture of resistance (already much discussed, but not surpassed) to these devices by many teachers, its recreational use also persists. In view of this demand, this article, which consists of an experience report, aims to demonstrate the execution of a teaching and learning proposal based on Biology and
\end{abstract}


Chemistry, which sought to perceive possibilities and limitations to the use of mobile digital technologies - $\mathrm{m}$-learning-and computers via sustained hybrid teaching methodology. This proposal, which occurred in a public high school in Cuiabá, MT, focused on the prevention of infectious diseases potentially transmissible by the handling of digital devices. A prototype of a mobile application and a blog were used in the process, to supply as digital media tools, searching for a potential framework in the learning theory of George Siemens, the Connectivism. The information in these objects would appear as nodes in an information network, receptive to the feedback of the students, as active participants of that same network. In the experience, diverse obstacles were evident for the implementation of practices of such nature and purpose in the public school, particularly, of formative, logistic and recursive scope. Something that warns those interested in these actions, caution in its planning and execution. However, plausible alternatives can also be considered, showing that teaching and learning based on digital methodologies and networks is not impossible for this sector as opposed to basic education, since it is advocated by international organizations such as UNESCO.

Keywords: Health; Hygiene; Hybrid teaching; Connectivism; Mobile phones.

\section{Manos de limpieza con tecnologías digitales}

\section{Resumen:}

Las tecnologías digitales están muy extendidas entre los jóvenes, personificado principalmente por los teléfonos móviles y teléfonos inteligentes modernos, como herramientas prácticamente omnipresentes en la vida diaria. A pesar de la repetida la cultura de la resistencia (ya muy discutido, pero no superó) a estos dispositivos por muchos profesores, su uso recreativo también persiste. Ante esta demanda, en este artículo, que consiste en un relato de experiencia, tiene como objetivo demostrar la implementación de una propuesta de enseñanza-aprendizaje basado en la biología y la química, la cual trató de darse cuenta de las posibilidades y limitaciones al uso de las tecnologías digitales móviles - $\mathrm{m}$-learning - y ordenadores a través de la metodología híbrida sostenida de la enseñanza. Esta propuesta, que se llevó a cabo en la escuela pública secundaria en Cuiabá, MT, tuvo como enfoque temático prevención de las enfermedades infecciosas potencialmente transmisibles por el manejo de dispositivos digitales. Un prototipo de aplicaciones móviles y un blog se utilizaron en el proceso de dar fruto como herramientas de medios digitales, la búsqueda de un marco potencial en George Siemens teoría del aprendizaje, Conectivismo. La información de estos objetos se establecería como nodos en una red de información y receptivos a los comentarios de los estudiantes como participantes activos en esta red. En el experimento, varios obstáculos eran evidentes en la aplicación de una similar naturaleza y el propósito prácticas en las escuelas públicas, en particular en la formación, la logística y el nivel recursivo. Algo que advierte interesados en estas acciones, cauteloso en su planificación y ejecución. Sin embargo, las alternativas plausibles también pueden ser considerados, lo que demuestra que las metodologías de enseñanza-aprendizaje basado en redes digitales y no es imposible que este sector como luchado y sufrido de la educación básica, como se recomienda por organizaciones internacionales como la UNESCO.

Palabras clave: Salud; Higiene; Educación híbrido; Conectivismo; Celulares.

\section{INTRODUÇÃo}

A juventude está profundamente imersa na cultura das tecnologias digitais, as quais personificam a geração atual, que desde tenra idade já manifesta desenvoltura ao lidar com tais ferramentas. Aparelhos celulares modernos, os ditos smartphones, estão incorporados ao 
cotidiano das pessoas, de tal forma que poderíamos considerar tais equipamentos, literalmente, como extensões de seus próprios corpos. "Alguns autores chegam mesmo a dizer que estamos em uma situação na qual máquinas e seres humanos estariam fundidos em uma espécie de amálgama" (BRASIL, 2013).

Muitos jovens também se utilizam dessas tecnologias. Na sala de aula, no transporte público, na recepção de um consultório médico, na sala de estar e mesmo, nos sanitários. Na sala de aula, ao carregar as baterias de seus aparelhos, muitas vezes os estudantes os deixam em contato direto com o chão. Consideramos, neste aspecto, a existência de um risco potencial para aquisição de doenças pelos estudantes, dada a exposição a agentes infecciosos presentes na superfície desses aparelhos, concomitante ao seu contínuo manuseio. Considera-se assim, que a lavagem de mãos é um modo adequado para prevenir doenças infecciosas transmitidas via contato manual.

A lavagem de mãos tradicionalmente é recomendada aos serviços hospitalares e ambulatoriais, via protocolos específicos, por organismos internacionais como a Organização Mundial da Saúde (OMS) e o CDC (Centro de Controle de Doenças), sendo voltados, portanto, para médicos e profissionais de enfermagem. Tais protocolos orientam os profissionais acerca de técnicas e materiais necessários para lavagem de mãos, antes e após a realização de procedimentos em pacientes. Existem várias categorias de lavagem de mãos para ambientes hospitalares e, dentre as quais, a lavagem de mãos simples com água e sabão, tem se mostrado relativamente eficaz. Entretanto, leituras recentes, como a Abreu, Melo, Rodrigues e Ferreira (2016) demonstram que a recomendação para adoção desta prática entre estudantes da área de Saúde é de extrema importância, e segundo o CDC deverá ser extensiva a todos os segmentos da sociedade.

Diante de tais circunstâncias, este trabalho consiste em um relato de experiência acerca de uma proposta de ensino-aprendizagem unificada entre Biologia e Química que teve como temática a questão da higienização de mãos, baseada no uso de TDICs (Tecnologias Digitais de Informação e Comunicação) via metodologias sustentadas de ensino híbrido, em escola da rede estadual de ensino de MT. O ensino híbrido, estratégia detalhada pelo Clayton Christensen Institute, dos EUA, propõe duas linhagens de ensino híbrido, a saber: a sustentada (com mescla de práticas de ensino tradicionais a modernos recursos tecnológicos) e disruptiva (inovação pautada em práticas pedagógicas totalmente diferentes daquelas adotadas anteriormente por uma escola). Diante dessa síntese, optou-se adotar estratégias sustentadas de ensino híbrido, como a rotação por estações e laboratório rotacional, que serão pormenorizadas mais adiante neste 
trabalho. Neste sentido, surge uma questão central: a escola pública, com sua contingência de recursos e insumos seria um espaço viável para a adoção dessas metodologias? Quais são as limitações e possibilidades de se realizar um trabalho significativo, portanto, do âmbito da educação em saúde recorrendo a tecnologias da informação e comunicação de rede?

Manter as mãos limpas é um dos passos mais importantes que podemos tomar para evitar doenças e propagar germes para outras pessoas. Muitas doenças e condições se espalham por conta da não lavagem das mãos, com sabão e água corrente limpa (CDC, 2015).

A higienização das mãos apresenta as seguintes finalidades (CDC, 2002; BRASIL, 2007): remoção de sujidade, suor, oleosidade, pelos, células descamativas e microbiota da pele, interrompendo a transmissão de infecções veiculadas ao contato; prevenção e redução das infecções causadas pelas transmissões cruzadas (BRASIL, 2009).

Conforme a OMS atesta em suas diretrizes de higiene para sistemas de saúde (http://www.who.int/gpsc/5may/tools/who guidelines-handhygiene summary.pdf), a limpeza das mãos é a medida principal para reduzir contaminações, tanto no caso de médicos quanto pacientes. Também é a providência mais simples que uma pessoa pode tomar para garantir que suas mãos estejam livres de germes (EMERSON, 2016).

O espaço da escola é especialmente importante para aprendizagens básicas de saúde. A própria aprendizagem escolar se relaciona com o desenvolvimento da saúde individual, uma vez que se constitui em espaço de aquisição de informação sobre si, sobre o mundo, sobreas relações sociais (CECCIM, 2006). Onde, “...é importante conectar sempre o ensino com a vida do aluno" (MORAN; MASETTO; BEHRENS, 2000).

A Pesquisa Nacional de Saúde do Escolar (PeNSE), uma publicação integrada do IBGE com o Ministério da Saúde, reporta a importância da temática deste trabalho, uma vez que a saúde, associada ao bem-estar físico por ela proporcionado, é condição fundamental para garantir bom desempenho da comunidade escolar em suas atividades.

De acordo com o PeNSE IBGE 2016, a Região Centro-Oeste situa-se entre as regiões em que os jovens e adolescentes possuem maior acesso a tecnologias móveis de comunicação, ou seja, celulares e smartphones. "Os dados de 2015 revelaram que 87,4\% dos escolares brasileiros do 9o ano responderam possuir aparelho celular. Esses percentuais foram maiores nas Regiões Sul (92,6\%) e CentroOeste (89,6\%)" (PeNSE, 2016). Em contrapartida, a Região Centro-Oeste: 
Apresenta o menor percentual de alunos em escolas da rede pública que informaram possuir pia ou lavatório em condições de uso, com acesso à água, além de sabão. Esse resultado ocorre principalmente pela falta de sabão para a limpeza das mãos na rede pública, onde apenas $56,7 \%$ desses alunos têm acesso a sabão (na rede privada esse percentual é de 96,8\%)[...]. A oferta de sabão pelas escolas públicas é a principal dificuldade a ser superada no Brasil para que se garantam condições adequadas de higiene aos alunos (PeNSE, 2016, p.33).

E essa conexão entre acesso a tecnologias digitais e higiene de mãos pode ser explicitada no excerto abaixo:

\begin{abstract}
Uma pessoa na sua escola ou trabalho está gripada. Os vírus das vias respiratórias que estão em suas mãos contaminadas são transportados para todos os objetos que essa pessoa gripada manuseou ao longo do dia. Tempos depois, você chega à sala que a pessoa doente esteve utilizando. Você usa o mesmo mouse e teclado, fala ao telefone e apoia suas mãos na mesma mesa. De repente, você sente uma leve coceira nos olhos e inocentemente usa a mão para coçá-los. Pronto, você acabou de levar os vírus que estavam no ambiente para dentro do seu corpo. O fato é que existe uma grande chance de você ficar doente mesmo sem nunca ter encontrado a pessoa que lhe passou o vírus. Se a pessoa gripada tivesse o hábito de lavar as mãos após contato com suas secreções, ela evitaria a contaminação de objetos utilizados por outras pessoas. Por outro lado, se você tivesse o hábito de lavar as mãos antes de levá-las aos olhos ou à boca, provavelmente não teria se contaminado (PINHEIRO, 2016, online).
\end{abstract}

Neste sentido, refletir acerca de uma situação com tal contexto, parece um acréscimo de desafios para os professores, que lidam com o persistente uso recreativo dos celulares pelos discentes na sala de aula, ainda que haja leis coibindo a prática em diferentes estados brasileiros. Um dissenso de fato, porque no estado de São Paulo o celular já começa a ser liberado para uso com fins pedagógicos, a partir de proposta do Secretário de Educação José Renato Nalini. É possível que essas tecnologias tenham muitas potencialidades nos processos de ensino-aprendizagem, pois “...procuram aproveitar este universo cibercultural para dele extrair sentidos de participação e interesse para as atividades curriculares" (BRASIL, 2013).

Hoje sabemos que a aprendizagem de mídias e tecnologias em contextos educativos é um processo complexo, no qual interveem um número de variáveis e fatores associados não só com os atributos internos dos meios tecnológicos (conteúdo, hardware, formas de representação e sistemas codificação de informação...), mas também com temas próprios (como o conhecimento prévio, atitudes, idade, estilos cognitivos...) e variáveis de contexto que usam a mídia ou material (trabalho feito com a mídia, objetivos educacionais e método de ensino em que o material é pedagogicamente integrado) (AREA MOREIRA, 2016, p.145 - tradução própria). A argumentação do autor corrobora que a inserção do celular no contexto da sala de aula, necessita, portanto, estar integrada a uma articulação pedagógica prévia. Entretanto, é 
importante conhecer também os insumos de rede, que se dispõe para execução dessas propostas. As escolas de educação básica da rede pública são marcadas pela deficiência de recursos, de acesso à rede de internet e pelo sucateamento de equipamentos digitais ou mesmo, pela inexistência dos mesmos.

Silva e Barbosa (2016) também reforçam a necessidade de planejamento, que deve ser feita de forma responsável e planejada. Acrescentando que: “No Ensino de Ciências, a disponibilidade dos recursos inovadores desperta nos alunos maior interesse pelo que está sendo trabalhado. Conceitos abstratos ganham significado, e a aprendizagem acontece com mais estímulo e prazer" (DA SILVA e BARBOSA, 2016, p.6-7).

Apesar de tantas deficiências e problemas estruturais, está acontecendo uma busca de alternativas de setores educacionais importantes, públicos e privados. Esse movimento se intensificará muito proximamente, porque as crianças não aceitam um modelo vertical, autoritário e uniforme de aprender (MORAN, 2015). É por conta dessas demandas, inclusive, que a aprendizagem móvel deve ser considerada como possibilidade recursiva.

A presença de dispositivos móveis nos sistemas formais de educação vem aumentando. Em nível global, dois dos modelos mais populares de aprendizagem móvel nas escolas são programas do tipo 1:1, ou Um Computador por Aluno (UCA), em que cada aluno recebe o seu próprio dispositivo, sem custos para o aluno ou para a sua família, e os do tipo Traga o Seu Próprio Dispositivo (Bring Your Own Device - BYOD), que conta com que a maioria dos alunos tem os seus próprios dispositivos. [...] Como era de se esperar, o modelo UCA tende a ser mais comum em países e regiões mais pobres, enquanto a estratégia BYOD costuma ser implementada em comunidades mais abastadas, onde praticamente todos os alunos têm um dispositivo móvel (UNESCO/NOKIA, 2014, p.16).

A aceitação do grande potencial dos programas 1:1 parece ser universal, mas qual é a melhor maneira de usá-los para apoiar a aprendizagem é uma pergunta que permanece sem resposta (UNESCO/NOKIA, 2014, p.20). É neste sentido, que a aprendizagem móvel deve ser incentivada também no Brasil, pois de acordo com dados apresentados do PeNSE, um considerável percentual de estudantes da região Centro-Oeste possui celulares e este fato pode potencializar a difusão da metodologia do ensino híbrido nas escolas.

O ensino híbrido é apresentado por Moran (2015) como um blended, inerente a uma aprendizagem também híbrida, que não acontece apenas no cotidiano da sala de aula, mas nos múltiplos espaços de convivência, inclusive os digitais. Tratando-se de “...um programa de 
educação formal no qual um aluno aprende, pelo menos em parte, por meio do ensino online, com algum elemento de controle do estudante sobre o tempo, lugar, modo e/ou ritmo do estudo, e pelo menos em parte em uma localidade física supervisionada, fora de sua residência" (CHRISTENSEN et al., 2013).

E sem dúvida, como é exposto em Brasil (2012), os professores e professoras, podem ser mediadores importantes neste processo de produção e participação da produção dessas novas arenas educacionais que são apresentadas no cenário da cibercultura e das novas tecnologias de informação e comunicação. O ensino híbrido se inclui nessa seara. Onde o professor “... é um provocador de conflitos; suporte e apoio no processo; mediador; constrói junto com os alunos; preocupa-se com o processo e não apenas com o produto" (BERNI, 2006). Ponderamos que a cultura da resistência consoante à conduta de muitos a docentes, não deve ser tomada como intransigência. 0 professor na verdade, ainda é um ente alijado de formação para essa realidade tecnológica que se surge (ou se insurge) nas escolas. Necessita reconhecer e aceitar a demanda formativa necessária para integrar pedagogicamente os dispositivos móveis na sala de aula. E deve interagir com seus pares nas escolas no sentido de solicitar formação específica para essa tarefa, junto aos setores pertinentes de formação continuada, que espelha uma conquista laboral, social e política dos professores da rede pública de ensino. Dessa maneira, haveria um princípio de enfretamento para o alijamento, deixando de ser a formação para uso pedagógico de TDICs, uma possibilidade ao alcance apenas de quem pode pagar por cursos mercantilizados por organizações existentes para tal finalidade.

A transformação do professor como orientador ou mediador no processo de construção do projeto pessoal de cada estudante incide, ferozmente, sobre o papel do docente - que já não mais detém, soberanamente, a informação. Portanto, não é o responsável por ensinar tudo, pois sua formação nunca é totalizada. Isto requer a formação continuada e a busca constante de conhecimentos seja na investigação e aprimoramento dos conhecimentos seja na troca com seus estudantes. A formação docente é cambiante (CASTRO et al., 2015, p.57).

Além de ser mediador no processo híbrido de ensino, pode integrar diferentes componentes curriculares numa proposta de ensino de práticas higiênicas, como na temática da importância da lavagem de mãos apresentada neste trabalho. Tal integração evocaria processos interdisciplinares, onde: a Biologia traz o mundo dos micróbios patogênicos, o celular e os hardwares como fômites potenciais, justificando a necessidade de mãos limpas para prevenir doenças infecto contagiosas. Fômites, por sua vez, são quaisquer objetos contaminados por microrganismos ou ovos de geo-helmintos e potencialmente causadores de doenças. O celular é um equipamento que permanece em contato constante com as mãos e superfícies, podendo 
assim, sofrer deposição de células descamativas da pele e consequente acumulo de uma verdadeira biota de microrganismos. Disto decorre a importância da higiene, principalmente da lavagem de mãos. A Química diz respeito aos sabões como insumos de higienização, com propriedades e mecanismos de ação peculiares. E de ambas as disciplinas ou componentes curriculares, deveria emergir a reflexão final acerca dos reveses baseados nos impactos ambientais que o processo de higienização traz para o meio ambiente, de modo geral. Trata-se de uma proposta de integração de componentes curriculares que busca, portanto, se alinhar com a interdisciplinaridade.

Segundo Fazenda (2003) a interdisciplinaridade, enquanto ferramenta mediadora do conhecimento conceitua-se pedagogicamente por meio da integração entre os docentes. Tal integração é proveniente do diálogo e de objetivos em comum em determinados conhecimentos entre as disciplinas. Efetivar a interdisciplinaridade é uma tarefa árdua devido a dois fatores: o primeiro deve-se a falta de entendimento de seu significado e o segundo é a dificuldade de colocá-la em prática, entretanto além dos conceitos mal construídos esbarram-se ainda nos problemas práticos oriundos das formações estanques. Essas dificuldades devem ser superadas para que os reais objetivos sejam alcançados (HARTMANN e ZIMMERMANN, 2007). Entende-se como objetivos comuns para tais disciplinas ou componentes curriculares, a manutenção da saúde, tão necessária quanto, em tempos de tamanha percussão realizada nos dispositivos digitais, objetos que por sua vez, contém alta valoração material para os jovens.

Além do mais, os jovens devem utilizar critica e seguramente as tecnologias, na possibilidade de utilizá-las como fontes de conhecimento e não serem subjugados por elas (BRASIL, 2013).

Por essa razão, além da importância das TDICs e da provável viabilidade da aprendizagem móvel personificada pelos celulares e smartphones na sala de aula, como ferramentas pedagógicas, se faz necessário o encaixe dessas ações a uma teoria de aprendizagem capaz de contemplar a ascensão das tecnologias digitais dentro dos espaços escolares, algo que o Conectivismo de George Siemens se propõe a fazê-lo.

Neste sentido, Foresti e Teixeira (2012, p.61), recompilando os conceitos conectivistas de George Siemens esclarecem que a aprendizagem potencializada pelas Tecnologias Digitais de Rede possui como principais elementos inseridos, a capacidade de formar conexões e reconhecimento de padrões que complementam esses conceitos. 
A conexão e o reconhecimento de padrão são duas das atividades preparatórias da aprendizagem. Através da formação de conexões entre os nós da rede, cada nó alterado atinge todos os demais instaurando o fluxo de informações. Esses nós podem ser pessoas, objetos e conteúdos. [...] Nessa concepção, Siemens acredita que alguns processos estão envolvidos na aprendizagem, como: a capacidade de discutir, dialogar e feedback. Assim, o verdadeiro valor da discussão, do debate e do diálogo está nas conexões formadas entre indivíduos, cuja sociedade, essencialmente, é um espaço de formação de conexões (FORESTI e TEIXEIRA, 2012, p.61).

Percebe-se que o feedback é o retorno da mensagem recebida e enviada, é a retroalimentação da informação e uma maneira de verificar se o objetivo traçado foi alcançado. Em sala de aula, por exemplo, pode ocorrer por meio de diálogos e trabalhos práticos. Nesse passo, para que a aprendizagem de Siemens ocorra, precisa-se estar inserido em um contexto de aprendizagem em rede potencializada pela conectividade.[...] Para que haja a aprendizagem colocada por Siemens, dentro do contexto e apoiada nesses processos, é preciso que o sujeito assuma o papel de nó ativo na rede (FORESTI e TEIXEIRA, 2012, p.62).

\section{MATERIAIS E MÉTODOS}

Buscando implementar uma proposta pedagógica de ensino híbrido para abordar técnicas higiênicas preventivas, este relato de experiência envolveu o uso concomitante de técnicas sustentadas do método híbrido de ensino: a rotação por turmas, laboratório rotacional e a sala de aula invertida. As tecnologias digitais a serem utilizadas, do ponto de vista dos hardwares e dispositivos digitais, envolveram aparelhos celulares dos estudantes e computadores alocados no laboratório de informática de uma unidade escolar, localizada na região metropolitana de Cuiabá. A presente unidade que sediou a atividade descrita neste trabalho, por questão de privacidade, será denominada "Escola A":

(...) o rodízio entre estações, consiste em proporcionar ao aluno a possibilidade de circular, dentro da sala de aula, por diferentes estações, sendo uma delas uma estação de aprendizagem on-line, outra de desenvolvimento de projeto, trabalho em grupo ou interagindo com o professor, tirando dúvidas. Um segundo subgrupo é o rodízio entre laboratórios, no qual o aluno circula em diferentes espaços dentro do campus, sendo um deles o laboratório no qual ele realiza atividades online, ou laboratórios para o desenvolvimento de práticas específicas. [...] o quarto subgrupo, denominado sala de aula invertida (flipped classroom) (VALENTE, 2014, p.85). 
A aula invertida baseia-se na orientação docente sobre um conteúdo, com prescrição de atividades online aos estudantes, que serão realizadas em local externo à escola, no caso, na residência dos mesmos, eventualmente, ou onde disponham de acesso à rede de internet.

O laboratório rotacional também é descrito como um local onde: “os estudantes usam o espaço da sala de aula e o laboratório de informática ou outro espaço com tablets ou computadores, pois o trabalho acontecerá de forma on-line. Assim, os alunos que forem direcionados ao laboratório trabalharão nos computadores individualmente, de maneira autônoma, para cumprir os objetivos fixados pelo professor, que estará, com outra parte da turma, realizando sua aula da maneira que considerar mais adequada" (MORAN e BACICH, 2015).

Duas ferramentas foram utilizadas na proposta de atividade relativa à higienização das mãos: um blog, chamado CienTI (http://cientdics.blogspot.com.br/) e um aplicativo de celular, em processo de construção, denominado SAMBI - Saúde Mediada pela Biologia (http://app.vc/sambi). Ambos foram utilizados com o propósito de serem nós de conteúdos e possibilitar um futuro fluxo de informações, além de serem locus para futuros feedbacks dos estudantes.

Em decorrência do conteúdo programático de Biologia voltar-se para o estudo dos Reinos de Seres Vivos, a temática dos microrganismos e da higiene tem associação com o estudo de procariontes, vírus, fungos e helmintos. Em Química, esses estudantes já haviam estudado Soluções, e, portanto, supostamente teriam melhores condições de compreender os processos relativos à ação do sabão na remoção de sujidades das mãos. A escolha da turma foi aleatória por uma das autoras deste trabalho. Tais estudantes foram convidados a participar da experiência, com a condição de que seus pais ou responsáveis assinassem termos de consentimento livre e esclarecido, autorizando-os formalmente o ingresso dos jovens na referida proposta pedagógica, conforme determina a Resolução 466/2012 CNS do Ministério da Saúde. Uma vez autorizados pelos responsáveis, os menores de dezoito anos assinaram o Termo de Assentimento. Houve participação de todos os trinta e oito estudantes matriculados na sala de $2^{\circ}$ ano do ensino médio participante da pesquisa, onde dezesseis foram considerados aptos para a pesquisa e dentre os tais, apenas dez entregaram atividades válidas para fins de coleta de dados. Considerou-se apto, o estudante que entregou Termo de Assentimento e Termo de Autorização assinado por si e seus responsáveis legais. Foram empregadas três aulas semanais para execução da aula híbrida, ou seja, aproximadamente 180 minutos de duração, considerando tempo adicional.

A mencionada "Escola A", onde se efetuou a proposta de ensino híbrido situa-se em um 
bairro da zona norte de Cuiabá e atende somente ao ensino médio, regular e profissionalizante. Essa escola, de acordo com dados do site QEdu (2015) possui trinta computadores disponíveis para atividade discente em seu laboratório de Informática. Porém na ocasião da mesma, apenas seis conjuntos de computadores, teclados e mouses foram apresentados como funcionais. A rede de internet local é Wi-fi, de baixa velocidade, o que ocasiona constantes oscilações no suprimento de sinal em horários de grande demanda por parte da secretaria, coordenação pedagógica e sala dos professores. O sistema operacional disponibilizado para tal escola, a exemplo de outras instituições públicas, é o Kernel Linux.

Para consecução do ensino de técnicas de lavagem de mãos, visando a prevenção de doenças infecciosas e considerando o enfoque químico, foi elaborado um plano de aula e um roteiro, sendo que este último foi entregue a todos os participantes. Os estudantes tiveram liberdade para conduzir suas atividades individualmente ou em duplas.

Almejava-se dividir o laboratório em quatro estações distintas, cada qual, com uma atividade associada. Na estação 1, os alunos fariam leitura do texto De mãos limpas na era das tecnologias digitais, presente no blog CienTI. Na estação 2, depois de acessar o aplicativo SAMBI, seriam convidados a construir esquemas sobre doenças infectocontagiosas, a partir de abas enumeradas do referido aplicativo.

Esquemas são importantes, enquanto uma estratégia de leitura, haja vista que é um procedimento pontual que auxilia na compreensão do texto. É um gênero simples, na maioria das vezes, quanto à sua estrutura, entretanto requer uma leitura minuciosa, uma vez que as ideias mais significativas devem estar em destaque, enquanto que ideias secundárias devem estar subordinadas a esta. Os esquemas, em avaliações, podem assumir outras características, além daquela de resumir um texto-fonte. No ENEM, diversos esquemas aparecem com a função de complementar o texto escrito anteriormente, a fim de facilitar a compreensão de uma ideia para o aluno (DIONÍSIO, 2013).

Foram também instados a enriquecer os esquemas construídos a partir de recursos como links, disponibilizados no aplicativo. A estação 3, propunha que os alunos acessassem um botão do aplicativo chamado Atividades com o Sambi, onde participariam de uma dinâmica chamada Sint, criando um desfecho (feedback) para o pequeno parágrafo que encerrava o contexto de um processo infeccioso, onde mãos seriam meios para infecção cruzada. Na quarta e última estação, em sala de aula, participariam de uma oficina de lavagem higiênica de mãos, seguindo os seis passos preconizados pela OMS (Organização Mundial da Saúde). Como partes do processo avaliativo da proposta, devidamente munidos de seus próprios recursos para acesso à internet, 
eles acessariam o blog para postar um comentário crítico acerca da proposta, com base em leitura indicada e opiniões pessoais, enriquecidas com o suposto conhecimento adquirido pelas leituras e atividades realizadas.

Com isso, esperava-se no planejamento da proposta, obter dos estudantes: foco para realizar a leitura do blog; abordagem das docentes que conduziram o trabalho no sentido de sanar dúvidas pontuais; aptidão para manusear o aplicativo e atingir as metas propostas para as estações sem incorrer na costumeira dispersão; atentar para a disposição do grupo na realização dos procedimentos de higienização das mãos, aprendendo a técnica para realizá-la cotidianamente. Com este aprendizado, os jovens seriam instados a agirem como multiplicadores desse conhecimento em seus lares e comunidades. O enfoque da química traria reflexões futuras sobre a viabilização de insumos e locais adequados para higienização de mãos na escola com mínimos custos e impactos para o meio ambiente.

\section{RESULTADOS E DISCUSSÕES}

\section{Resultados logísticos e de ensino-aprendizagem}

Os primeiros estudantes a adentrar o laboratório, se apressaram para sentar-se diante dos poucos monitores disponíveis. Os demais, conforme entravam, chegavam a reclamar que todos acabariam amontoados na estação 1 para ler o blog, pois o espaço não comportava toda a turma. Fracionar a turma à entrada e dosar seu acesso não foi permitido, porquanto os estudantes não podiam ficar no pátio esperando outros grupos concluírem leituras. Temendo transtornos com agentes de pátio e coordenação pedagógica, todos entraram no laboratório de uma só vez. A sala de aula dessa turma dista consideravelmente do laboratório de informática e os alunos não quiseram se separar em duas turmas distintas para serem rotacionadas nos dois ambientes, alternando-se entre realização de oficina e atividades do laboratório de informática. Temiam que a turma que tivesse prioridade na saída para o laboratório, fosse mais beneficiada em termos de tempo para realizar as atividades propostas.

A realização da atividade com os estudantes, relativamente ao ensino híbrido rotacional por estações, mostrou-se inoperante de acordo com as dinâmicas de rotação ou rodízio entre estações e laboratório rotacionais, já descritas em materiais e métodos. A turma bastante numerosa não se alocou de modo organizado no laboratório de informática, que contava 
somente com seis conjuntos completos de computadores. Consequentemente, para a modalidade laboratório rotacional, certamente o ambiente mostrou-se defasado para essa proposta sustentada, devido ao sucateamento dos computadores, contingenciamento de rede e desktops disponíveis. Se os autores anteriormente mencionavam um computador para cada estudante, saliente-se que na verdade, apenas seis unidades funcionais estavam disponíveis. A estratégia de rodízios foi dissolvida e os alunos sentaram-se conforme a conveniência. Para dar prosseguimento com a atividade, e diante de um apelo coletivo do grupo, a técnica do laboratório realizou a inserção de senha de acesso à internet, em um a um dos celulares dos estudantes. Nem é preciso descrever o enorme dispêndio de tempo que essa ação provocou. Essa atitude intencionava evitar o "vazamento da senha" do laboratório para os estudantes.

Ao elaborar a aula, as docentes não contavam com tais adversidades, porquanto o texto que embasou os estudos sobre metodologia híbrida mostrou-se deficitário relativamente a tais contextos vivenciados no trabalho. No texto, mencionavam-se as dinâmicas segundo o contexto de escolas que possuem rede e dispositivos disponíveis para todos os alunos, o que não se aplicou à realidade da Escola $\mathrm{A}$, além de não haver uma descrição detalhada de como exatamente essas dinâmicas são operacionalizadas no curso das atividades. É quase um exercício de intuição e criatividade materializá-las nas salas de aula, sem aportes teóricos de apoio.

As atividades que eram rotacionais passaram, então, a ser cronometradas e sequenciais. A primeira atividade foi a leitura do blog e ocorreu também, a partir dos aparelhos celulares. Os estudantes que não conseguiram acessar a internet se sentaram em dupla com alunos que tinham condições de acesso à rede. Isso evidenciou flexibilidade, sociabilidade e interação do grupo. Logo que a leitura foi concluída, a atividade prevista para a estação 2, teve início. 0 aplicativo abria facilmente em celulares Android, sistema operacional presente na maioria dos aparelhos naquele momento. Os estudantes que permaneceram utilizando os computadores, não conseguiram abrir o aplicativo SAMBI via desktop em computadores que operavam com Linux. A escola conta com um laboratório financiado pelo governo federal; entretanto devido à sala numerosa e a capacidade de 3 GB ofertada, mostrou-se insuficiente, acarretando travamento dos computadores e lentidão nos celulares. Também foi possível observar que o programa gratuito Linux não acessa todos os programas solicitados.

A atividade de construção de esquemas demonstrou-se complexa e os estudantes tinham dificuldade para recolher as informações solicitadas nas abas do aplicativo para construí-los. Neste aspecto, construir o esquema "cru", com informações resumidas, foi um relativo avanço. 
O aplicativo, então protótipo de produto educacional de um programa de Mestrado Profissional, mostrou-se "duro", pois seu manuseio requeria auxílio docente constante e os alunos acharam as tarefas difíceis. Na realidade, ainda que haja necessidade de prover melhorias nas suas interfaces, muitos estudantes não são afeitos ao hábito da leitura, fato que dificultou o uso do aplicativo. Oito duplas de estudantes conseguiram realizar apenas a construção parcial de esquemas.

Cinco duplas de estudantes conseguiram fazer esquemas completos, mesmo sob condições adversas de oscilação do sinal de internet e progressivo "travamento" dos dispositivos; duas duplas foram além e realizaram a dinâmica Sint, prescrita para a estação 3. Essa dinâmica consistia em propor aos estudantes que finalizassem um contexto inacabado acerca da possibilidade de transmissão de doenças por mãos sujas. 0 referido contexto existe no aplicativo SAMBI e os estudantes teriam que fazer sua leitura e propor um final para a estória inserida na dinâmica. Na figura 1 temos a resposta dada por uma das duas duplas que fizeram as atividades propostas para as estações 2 e 3 :

Figura 1: Finalização de contexto proposto na dinâmica SINT - estudantes sugerem que a lavagem de mãos evita a transmissão de doenças

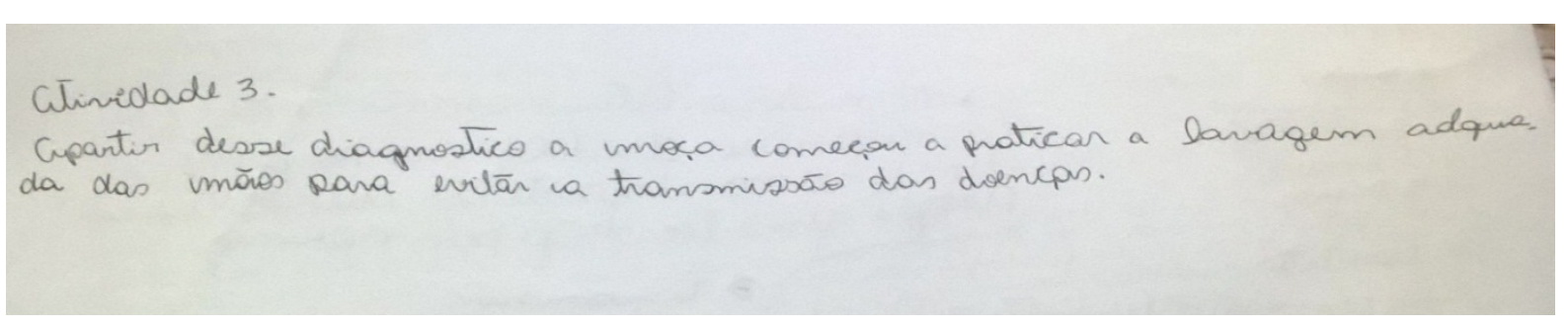

Fonte: própria.

O tempo para a aula no laboratório de informática cessou e os estudantes foram reconduzidos à sala de aula ao final da quinta aula, a terceira, entre as três aulas disponibilizadas para a prática. Nesse ínterim, um contingente se retirou com seus pertences, evadindo-se da escola por conta própria. Aproximadamente dezoito estudantes regressaram à sala de aula.

$\mathrm{Na}$ ocasião, as docentes de Química e Biologia concluíram o trabalho, sem que houvesse tempo para viabilizar a oficina de lavagem de mãos com os alunos. Na sala de aula foi realizada a discussão pelas docentes autoras, das disciplinas de Biologia e Química, dos textos lidos no blog, com assuntos estudados na Biologia e na Química respectivamente: doenças causadas e transmitidas pela falta de limpeza das mãos (resfriados, gripes, intoxicação alimentar, hepatite 
A, parasitoses intestinais e especialmente a gripe H1N1), história do sabão, substâncias, solubilidade e educação ambiental. Após a explanação, a professora de Biologia demonstrou aos presentes, sem os insumos água limpa e sabão, os passos da técnica para lavagem das mãos conforme preconiza a Organização Mundial da Saúde - OMS.

Alternativamente, a professora de Química propôs uma atividade individual aos alunos, baseada em releitura do blog CienTI e postagem de uma síntese a partir da temática abordada durante a proposta. É importante assinalar que haveria persistência em retomar a estratégia. Porém, os docentes de Mato Grosso, na ocasião, a exemplo dos demais servidores públicos estaduais, aderiram ao movimento grevista no sentido de reivindicar direitos enquanto categoria profissional. Assim, as aulas foram suspensas na semana seguinte à experiência. Entretanto, dois estudantes fizeram a atividade do blog solicitada pela docente de Química, evidenciando que a modalidade aula invertida, pode ser viável para a realidade das escolas públicas, conforme ilustram os fragmentos abaixo colhidos no blog:

Aluno 1: "eu entendi que se você não lavar as mãos ela pode transmitir inúmeras doenças causadas por bactérias, etc."

Aluna 2: "Pelo que vimos, a finalidade de um xampu é limpar os cabelos, os componentes do suor (gordura do cabelo) e a sujeira ambiental depositada no fio capilar. Entretanto, a remoção de todo o sebo natural torna o cabelo opaco, áspero e tornando-o difícil de pentear. Assim também vimos como é feito e suas composições químicas e como existe sabões/detergentes que causam alergias em pessoas e principalmente naquelas que trabalham com limpeza e não usam nem um tipo de proteção com as luvas. Vimos que se não lavarmos nossas mãos podemos acabar transmitindo doenças como a catapora, gripe (H1N1), sarna, resfriado e entre outras. Enfim devemos nos prevenir e fazer o que é certo pra nós e para não acabar transmitindo doenças para o próximo."

Percebe-se que a aluna 2 associa a lavagem de mãos como uma forma de prevenção segura para as pessoas e seus semelhantes. Conclui-se que, se uma intercorrência não tivesse cessado o calendário escolar, vários feedbacks como os tais obtidos nos fragmentos acima, seriam possíveis, comprovando a possibilidade de aprendizagem baseada no foco conectivista.

O conectivismo surge, portanto, como uma alternativa para o aprendizado que ocorre em rede e mediado pela máquina. A era digital, da qual somos testemunhas, exige ações sem que haja aprendizado pessoal (MATTAR, 2012, p. 17). Houve um deslocamento do conhecimento, que antes era interno, para o conhecimento exterior ao indivíduo. A estrutura conectada da rede não está limitada ao desenvolvimento de dados e informação, mas também possibilita 
desenvolver o conhecimento e a aprendizagem. O indivíduo não está totalmente no controle da aprendizagem (SILVA, 2014, p.77).

As informações em rede sofrem constantes mudanças e atualizações. Sendo assim, reconhecer e decidir sobre a relevância ou não de uma informação, exige do indivíduo uma capacidade de reconhecimento muito precisa. Essa é, portanto, uma habilidade fundamental para que o aprendizado em rede se concretize (SILVA, 2014, p.78). Onde, os indivíduos tiveram a oportunidade de ler, selecionar informações e articulá-las de modo a constituírem a um argumento, ou esforço de limiar na consecução desse processo. Se estiver em rede, significa que qualquer pessoa que acessar o blog e ler os comentários, poderá também interagir com os estudantes e elaborar uma resposta aos seus comentários, ou como resposta ao texto postado para leitura sobre higienização de mãos. E essa interação dialógica constitui um processo de aprendizagem, assumindo o papel de nó ativo na rede.

O grande desafio do uso das metodologias ativas está no estabelecimento da autonomia e da liberdade do educando, de modo que este participe ativamente do processo de ensinoaprendizagem, não como mero expectador ou reprodutor de informação, mas como indivíduo crítico, reflexivo e construtor do conhecimento (Freire, 1997). Nesse sentido, tornam-se também necessárias a reformulação do pensamento e da ação docente quanto ao seu papel educador, sinalizando para outro olhar sobre as práticas pedagógicas. Dessa forma, a educação transformadora visa à adoção de ações pedagógicas que reflitam a complexidade do tempo presente (OLIVEIRA et al, 2016, p.3).

Outro aspecto que vale ressaltar, é que eles, Nativos Digitais, são seletivos no quesito absorção do conhecimento. Neste mundo em que as informações surgem de maneira muito rápida e é imensa a quantidade disponível, nem tudo é importante. Logo, é necessário se concentrar naquilo que de fato é fundamental para eles e, quando algo tem pouca relevância, é descartado rapidamente, sem se dar a devida atenção (CARVALHO, OLIVEIRA e SILVA, 2015, p.5).

Pondera-se, também, que não houve adequada proporção entre os objetivos das atividades e o tempo disponível para realizá-las, sendo seu prosseguimento, portanto, impraticável, diante da circunstância anteriormente relatada.

Ainda que tenha ocorrido ingerência de tempo, falta de recursos e inadequações no plano e atividades, as docentes mantiveram boa interação recíproca na condução dos trabalhos, sendo possível correlacionar os conteúdos de sala de aula de forma harmônica, flexível, buscando fortalecimento do processo de ensino-aprendizagem, sem esmorecer ou retroceder 
diante das adversidades ocorridas no processo.

Para que haja a possibilidade de implantação do ensino híbrido é preciso quebrar as barreiras internas do ensino tradicional. É preciso ser cauteloso para que não vire um modismo que se esvazia quando não há consistência teoria que o sustente. Precisamos incentivar os docentes a fazer as experiências de sala de aula invertida e juntamente com isso investigar as reações e os resultados destas ações (CASTRO et al, 2015, p.57). Ainda que essas ações redundem em diversas tentativas e discussões dos sujeitos ativos no processo, até que haja alcance satisfatório dos objetivos e passos da metodologia, sem ficar estanque aos parcos recursos de rede e materiais, como os que se mostraram no ambiente. Mas atente-se, que o improviso é algo que, qualquer que seja a circunstância, deve ser definitivamente desencorajado e não confundido com a flexibilização necessária para consecução dessas propostas de metodologias.

\section{CONSIDERAÇÕES FINAIS}

A higienização de mãos é um hábito eficaz para prevenção de doenças. No entanto, sua preconização deve ser sistematizada em toda a sociedade e, não somente nos ambientes hospitalares. Este trabalho apresentou um panorama da logística de uma atividade que teve a intenção de estar alinhada às propostas do ensino híbrido, tematizando a questão da importância de uma prática higiênica como a lavagem de mãos, para a manutenção da saúde.

Celulares, tablets e teclados podem ser fômites que veiculadoras de agentes etiológicos causadores de doenças infectocontagiosas. Mãos higienizadas diminuem tal risco. Com base no título deste trabalho, sugerimos a condução de estudos sobre colonização bacteriana nos dispositivos digitais utilizados por escolares da educação básica e superior. Blogs e demais softwares, enquanto recursos concernentes às tecnologias digitais podem ser ferramentas úteis para a viabilização de atividades com vistas à prevenção de doenças e promoção da saúde e na realidade, são nós informacionais potenciais, vitais para o fluxo da informação. Tais instrumentos certamente ajudariam a difundir mais enfaticamente a cultura da lavagem de mãos na sociedade.

O ensino híbrido sustentado consta em si, como um excelente método para mediação pedagógica, mas deveras distante da realidade marcada por contingências de muitas escolas públicas. Uma realidade caracterizada pela oferta deficitária da rede de internet ou contenção deste recurso, prejudicando o processo de conexão inerente a propostas congêneres. 
Constatamos que a formação continuada dos docentes na metodologia do ensino híbrido, adequadas às condições de insumos das escolas, é fundamental para sua inserção nestes espaços. Trata-se de uma metodologia, que embora já seja contemplada no currículo de alguns cursos de formação docente, é vedada a pessoas leigas no processo, pois a distorção de seus objetivos pode agravar a resistência à inserção de TDICs e metodologias ativas na escola.

Entretanto, ainda acreditamos que a aula invertida é uma possibilidade que se encontra ao alcance de professores interessados na corrente conectivista e empenhados em inserir o ensino híbrido na realidade das escolas públicas, considerando que muitos escolares possuem acesso à rede em suas casas. 0 sistema de laboratório rotacional requer ao menos dois docentes trabalhando no processo, suscitando a motivação dos discentes em articulação hábil do tempo e atividades, que surtam como integradas entre o ambiente de sala de aula e laboratório. A rotação por turmas na verdade requer instrumentalização dos professores interessados na proposta, por meio de cursos, oficinas e leituras correlatas. Neste sentido,estudos sobre estratégias de flexibilização à integração de TDCIs e TDRs (Tecnologias Digitais de Rede) nas escolas públicas, considerando suas contingências, também devem ser considerados, a guisa do que "realmente temos em mãos para fazer algo neste sentido".

Os jovens e adolescentes, que são dinâmicos e afeitos à forma e imagens, em detrimento do predomínio do texto, possuindo grande apreço pelas redes sociais. Neste sentido, seria válida a busca por experiências de ensino-aprendizagem exitosas já realizadas com o uso desses componentes do ciberespaço.

Além da formação adequada, os professores devem se ater a planejamentos que também alcancem as pessoas com deficiência presentes no contexto da sala de aula. Se o mote foi suscitar um alijamento formativo e material, levar tais propostas adiante sem reconhecer a inclusão (ou sua necessidade), não será algo que mais do que mera hipocrisia.

A metodologia de ensino híbrido é uma inovação pedagógica e requer esforços para sua implementação. Entretanto, quando as ações são muito complexas e os objetivos parecem ser ininteligíveis para os estudantes, na verdade não há uma inovação em curso. Assim, é necessário ter como ponto de partida a simplificação das ações docentes, na medida do aporte teórico e metodológico que podem obter, para a progressiva obtenção de melhores resultados. 


\section{REFERÊNCIAS}

AREA MOREIRA, Manuel. La educación em el labirinto tecnológico: de la escritura a las máquinas digitales. SÃo Paulo: Cortez-Octaedro, 2016.

BACICH, Lilian.; MORAN, José Manuel. Aprender e ensinar com foco na educação híbrida. Revista Pátio, n.25, jun. 2015, p. 45-47.

BERNI, Regiane Ibanhez Gimenes. Mediação: o conceito vygotskyano e suas implicações na prática pedagógica. XI Simpósio Nacional de Letras e Linguística e I Simpósio Internacional de Letras e Linguística. Anais... Uberlândia, MG: UFU, 2006.

BRASIL. Agência Nacional de Vigilância Sanitária. Segurança do Paciente em Serviços de Saúde: Higienização das Mãos. Brasília: ANVISA, 2009.

BRASIL. Ministério da Educação. Secretaria de Educação Básica. Formação de Professores do Ensino Médio. Etapa I - caderno II: O jovem como sujeito do Ensino Médio. Versão Preliminar. Curitiba: UFPR, Setor de Educação. 2013.69p.

CARVALHO, Caio Abitbol; OLIVEIRA, Eloiza da Silva Gomes de; SILVA, Fabiana Triani Barbosa da. Aprendizagem e Tecnologias Digitais: novas práticas, jovens aprendizes. COLÓQUIO INTERNACIONAL EDUCAÇÃO, CIDADANIA E EXCLUSÃo (CEDUCE), v. 4, 2015.

CASTRO, Eder Alonso; COELHO, Vanessa; SOARES, Rosania; SOUZA, Lirek Kalyany Silva de; PEQUENO, Juliana Olinda Martins; MOREIRA, Jonathan Rosa. Ensino híbrido: desafio da contemporaneidade?. PROJEÇÃo E DOCÊNCIA, v. 6, n. 2, p. 47-58, 2015.

CDC. Show Me the Science - How to Wash Your Hands (2015). Disponível em: <http://www.cdc.gov/handwashing/show-me-the-science-handwashing.html> acesso em 04/06/2016.

CECCIN, Ricardo Burg. Saúde e doença: reflexão para a educação da saúde. In: MEYER, Dagmar E. Estermann (Org.). Saúde e sexualidade na escola. 3. ed. Porto Alegre: Mediação, 2006. 176 p.

CHRISTENSEN, C.; HORN, M.; STAKER, H. Ensino Híbrido: uma Inovação Disruptiva. Uma introdução à teoria dos híbridos. Clayton Christensen Institute for disruptive innovation. Maio de 2013. Disponível em < http://porvir.org/wp-content/uploads/2014/08/PT_Is-K-12-blended-learning-disruptive-Final.pdf > Acesso em 08/06/2016.

DA SILVA, Raimunda Leila; BARBOSA, Alessandro Rodrigues. ENSINO DE CIÊNCIAS E TECNOLOGIAS DIGITAIS: DESAFIOS E POTENCIALIDADES. Ciclo Revista, v. 1, n. 2, 2016.

DE ABREU, Rita Neuma Dantas Cavalcante; MELO, Carolina de Paula Lima; RODRIGUES, Angela Maria Uchoa; FERREIRA, Renata Carneiro. Saberes dos discentes de enfermagem sobre segurança do paciente: ênfase na higienização de mãos. Revista Enfermagem Contemporânea, v. 5, n. 2, 2016.

DIONÍSIO, Angela Paiva. Verbetes enciclopédicos: tabela e esquema. Recife: Pipa Comunicação, 2013. 59 p.

EMERSON, Sarah. Se você não usa o método de seis passos para lavar as mãos, você é nojento. Motherboard. 2016. Disponível em: http://motherboard.vice.com/pt br/read/metodo-de-seis-passos-para-lavar-as-maos acesso em 04/06//2016.

FAZENDA, Ivani Catarina. A. Interdisciplinaridade: história, teoria e pesquisa. 11. ed. São Paulo: Papirus, 2003.

FORESTI, Andressa; TEIXEIRA, Adriano Canabarro. Proposta de um conceito de aprendizagem para a era digital/Proposal a concept of learning for the digital age. Revista Latinoamericana de Tecnologia Educativa-RELATEC, v. 11, n. 2, p. 55-68, 2012.

HARTMANN, Angela Maria; ZIMMERMANN, Erika. O trabalho interdisciplinar no Ensino Médio: A reaproximação das "Duas”. Revista Brasileira de Pesquisa em Educação em Ciências, v. 7, n. 2, 2007. 
MORAN, José Manuel.; MASETTO, Marcos T.; BEHRENS, Marilda A. Novas tecnologias e mediação pedagógica. Campinas: Papirus, 2000.

MORAN, José Manuel. Mudando a educação com metodologias ativas. Convergências Midiáticas, Educação e Cidadania: aproximações jovens. Ponta Grossa: UEPG Foca. Coleção Mídias Contemporâneas, 2015.

PINHEIRO, Pedro. A importância de lavar as mãos. 2016. Disponível em <http://www.mdsaude.com/2015/10/lavar-as-maos.html> Acesso em 07/06/2016.

OLIVEIRA, Luiz Roberto de; CAVALCANTI, Lidia Eugenia; SILVA, Andréa Soares Rocha da; ROLIM, Raquel de Melo. Metodologias ativas de ensino-aprendizagem e suas convergências com as Tecnologias Digitais de Informação e Comunicação. Docencia e innovación. 2015.

OLIVEIRA DA SILVA, Edna Marta. Como aprende o nativo digital: reflexões sob a luz do conectivismo. REVISTA INTERSABERES, v. 9, n. 17, p. 68-80, 2014.

PeNSE. Pesquisa Nacional de Saúde do Escolar 2015/IBGE. Coordenação de População e Indicadores Sociais. Convênio: Ministério da Saúde, com apoio do Ministério da Educação. Rio de Janeiro: IBGE, 2016.132 p.

SILVA, Sidcleia Kécia Sidcleia Kécia Vieira; ARAÚJO, Thiago Laurentino; COSTA, Anderson Pereira; SILVA Marques Francisco da; COSTA, Ivaneide Soares da. Mãos limpas, corpo saudável: importância da higiene das mãos para a prevenção de doenças. I Seminário Nacional do Ensino Médio História, Mobilização, Perspectiva, 2011.1075-1085.

UNESCO/NOKIA. O Futuro da aprendizagem móvel: implicações para planejadores e gestores de políticas. Brasília: UNESCO, 2014. PDF disponível em: http://www.unesco.org/new/pt/brasilia/communication-andinformation/access-to-knowledge/ict-in-education/ Acesso em 11/07/2016.

VALENTE, José Armando. Blended learning e as mudanças no ensino superior: a proposta da sala de aula invertida Blended Learning and Changes in Higher Education: the inverted classroom proposal. Educar em Revista, v. 13083, p. 854, 2014. 